\title{
Sea Turtle Conservation: 10 Ways You Can Help ${ }^{1}$
}

\author{
Jessica E. Swindall, Holly K. Ober, Margaret M. Lamont, and Raymond R. Carthy²
}

Five species of sea turtles rely on Florida's coastal and nearshore habitats for nesting during the summer months and foraging throughout the year (Figure 1).

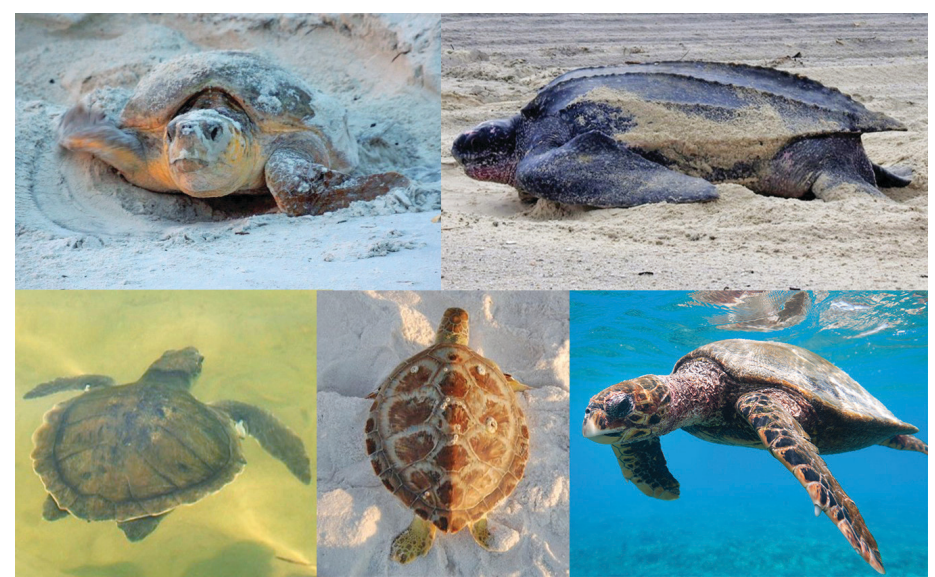

Figure 1. The five sea turtle species in Florida are the loggerhead (top left), leatherback (top right), Kemp's ridley (bottom left), green (bottom center), and hawksbill (bottom right).

Credits: Ximena Zornosa (top left), Nancy Thomson (top right),

Margaret Lamont (bottom left and center), and 4FR/gettyimages.com (bottom right).

- Loggerhead turtles, named for their large, block-shaped heads with strong jaw muscles for crushing benthic invertebrates, are the most common sea turtle species on Florida's nesting beaches. They nest on beaches throughout much of the state.

- Green turtles are unique among sea turtles in that they are largely vegetarian and can be spotted foraging in seagrass meadows.
- Leatherbacks, the largest species of sea turtle, are different from other turtles in that they are covered with a somewhat flexible "leathery" shell, rather than a hard shell. Leatherbacks can be seen in Florida's coastal waters but nest much less frequently in the state than loggerheads and green turtles.

- Kemp's ridley turtles are the smallest and most endangered marine turtle. They can be seen foraging in nearshore areas but rarely nest on Florida's beaches.

- Lastly, hawksbill turtles are named for their pointed beaks. They are mostly tropical but occasionally appear in the southernmost waters of Florida and very rarely nest in the state.

All of Florida's sea turtles are in danger of extinction, largely as a result of people's actions. However, there are simple steps Florida's residents and visitors can take to help these remarkable animals. Below are 10 suggestions for limiting further harm to sea turtles.

\section{Turn off lights, use wildlife-safe lighting, and avoid} bonfires near beaches. Sea turtles can become disoriented by artificial lighting. To reduce harm to turtles, refrain from using outdoor lights when turtles are nesting and hatching, from May-October. If you must have outdoor lighting, use fixtures that shield bulbs on the top and sides so light is directed downward and is not visible from the beach; use fixtures that are mounted low to the ground; or use bulbs that are less visible to sea turtles (Figure 2).

1. This document is WEC421, one of a series of the Department of Wildlife Ecology and Conservation, UF/IFAS Extension. Original publication date February 2020. Visit the EDIS website at https://edis.ifas.ufl.edu for the currently supported version of this publication.

2. Jessica E. Swindall, former graduate research assistant, Department of Wildlife Ecology and Conservation; Holly K. Ober, associate professor and Extension specialist, North Florida Research and Education Center; Margaret M. Lamont, biologist, US Geological Survey, Wetland and Aquatic Research Center; and Raymond R. Carthy, assistant unit leader, US Geological Survey_Florida Cooperative Fish \& Wildlife Research Unit; UF/IFAS Extension, Gainesville, FL 32611.

The Institute of Food and Agricultural Sciences (IFAS) is an Equal Opportunity Institution authorized to provide research, educational information and other services

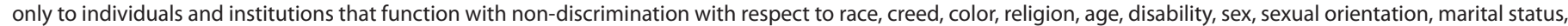

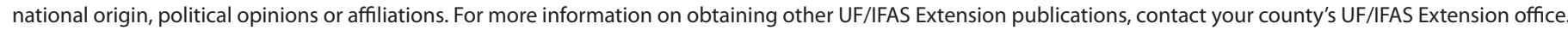
U.S. Department of Agriculture, UF/IFAS Extension Service, University of Florida, IFAS, Florida A \& M University Cooperative Extension Program, and Boards of County Commissioners Cooperating. Nick T. Place, dean for UF/IFAS Extension. 
Turtle-friendly bulbs use long-wavelength light (greater than $560 \mathrm{~nm}$ ), producing orange, amber, or red light. Also, be sure to prevent indoor light from escaping onto the beach by shielding windows with blinds, curtains, shades, or window tinting. Lastly, avoid lighting bonfires on or near beaches.

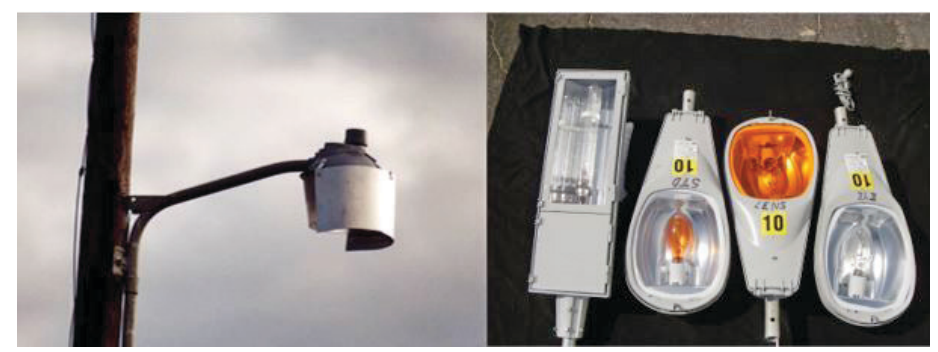

Figure 2. Light fixtures shielded on the top and sides direct light downward to reduce the likelihood of disorienting turtles on the beach (left). Examples of types of bulbs less likely to disorient turtles are (from left to right) low-pressure sodium vapor light, high-pressure sodium vapor fixture with specially coated amber high-pressure sodium vapor bulb (Eye Lighting International), high-pressure sodium vapor fixture and bulb with amber lens, and for comparison, a stock high-pressure sodium fixture and bulb. All except the fixture on the far right produce longer-wavelength light (>560 nm) which is less attractive to turtles.

Credits: Margaret Lamont

\section{Keep garbage off the beach and out of the water. Sea} turtles can become entangled in fishing line, ropes, and monofilament. They can also ingest plastic garbage that they mistake for food. Always properly stow trash when boating or jet-skiing to prevent it from ending up in the water, and throw away trash in garbage cans when on land (Figure 3).

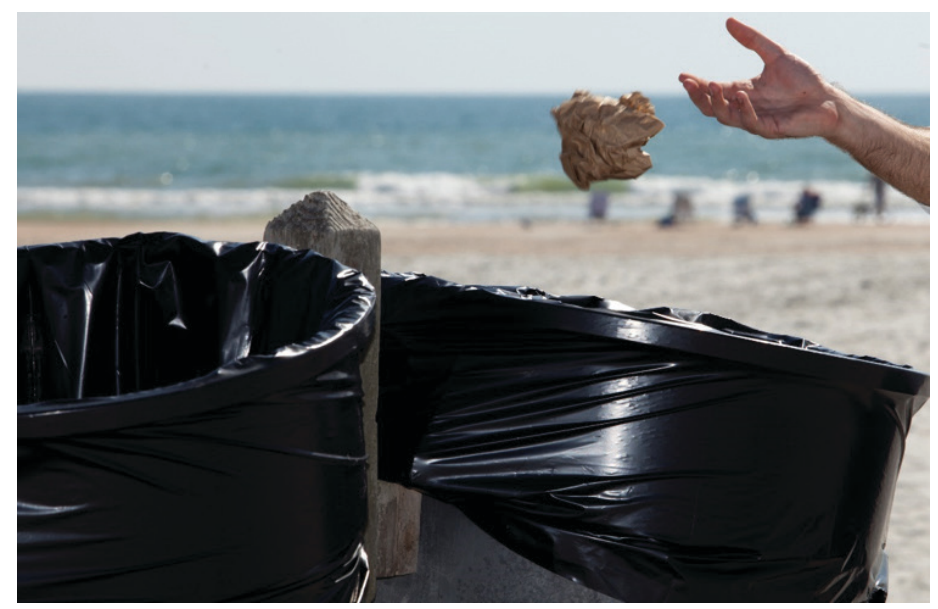

Figure 3. Throw all trash in garbage cans so it is not eaten by turtles, and so turtles do not get entangled in it.

Credits: Tyler Jones, UF/IFAS

\section{Do not disturb nesting or hatching sea turtles or sea}

turtle nests. During the months of May through October, sea turtles emerge from the ocean to nest on Florida's beaches. Although it is interesting to watch nesting sea turtles and hatchlings emerging from the nest, be aware that turtles are easily disturbed by human presence. Stay at least 50 yards from any turtles on the beach, and turn off all flashlights, lanterns, cellphone screens, or other light sources if it is after sunset. Also, do not disturb marked nests (Figure 4).

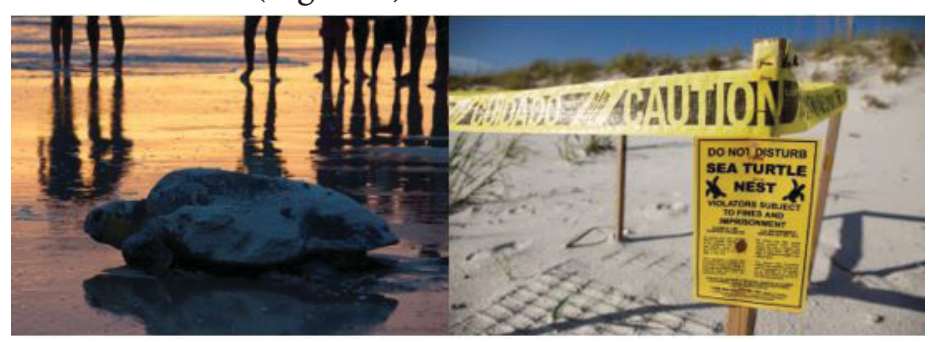

Figure 4. If you are present when sea turtles are on the beach, turn off all lights and do not disturb them as they crawl towards the ocean. Also, do not disturb marked nests where eggs have been laid. Credits: Ximena Zornosa (left) and Tyler Jones, UF/IFAS (right)

4. Protect seagrass beds. Seagrass beds are important nursery grounds for juvenile sea turtles because these areas provide shelter and necessary food sources (Figure 5). Gouging seagrass beds and creating trenches with boat propellers destroys this essential habitat. Always be aware of water depth and tide movement when boating in areas with seagrass to prevent damage to the beds from your boat propellers.

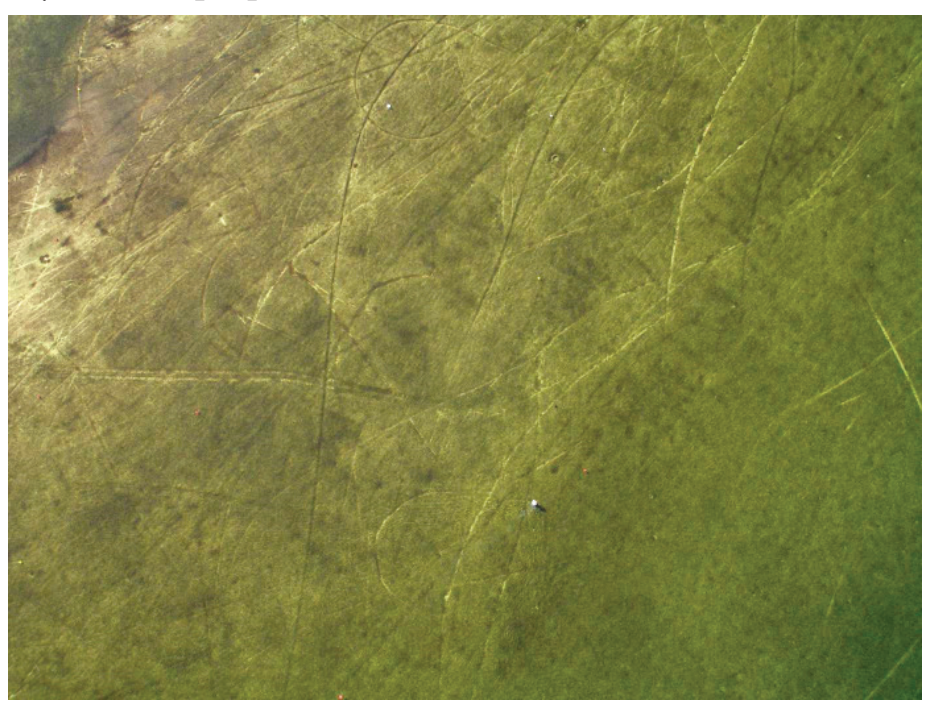

Figure 5. Avoid driving motorized boats in shallow waters where propellers can cause long-term damage to seagrass beds.

Credits: Florida Fish and Wildlife Commission

\section{Remove recreational equipment and furniture from} the beach at night. Adult female sea turtles crawl onto beaches to lay their eggs at night and can become entangled in recreational equipment and furniture left on the beach overnight (Figure 6). Newly hatched sea turtles emerging from their nests can also become entangled in items people leave on the beach as they crawl to the water. Be sure to remove all toys and furniture from the beach 
each evening to provide a clear path for nesting and hatching sea turtles.

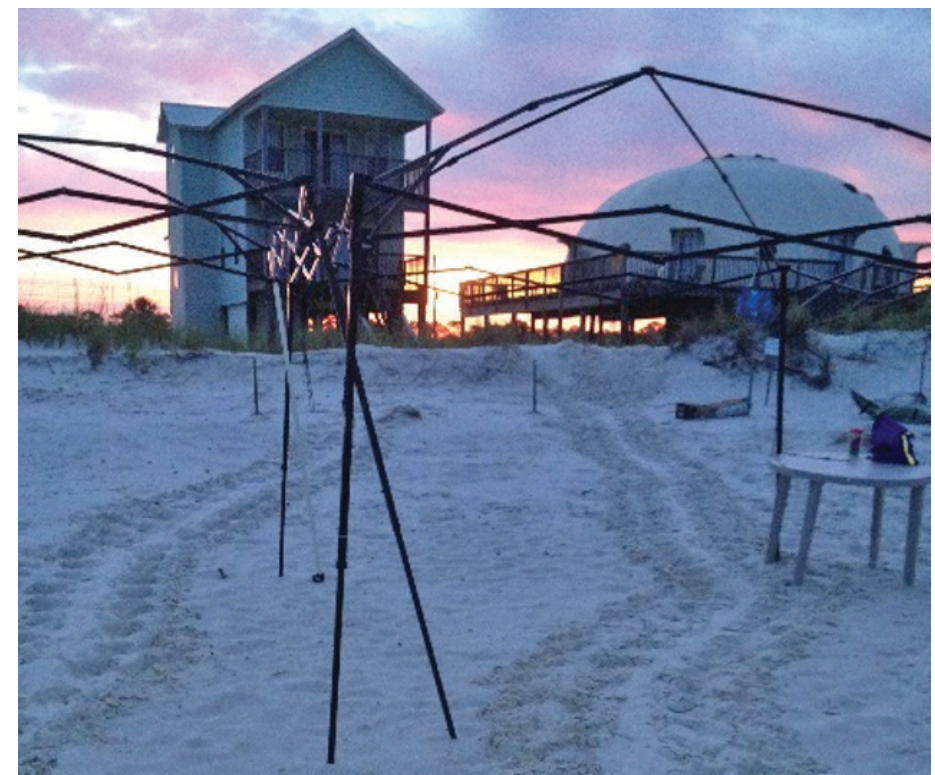

Figure 6. Sea turtles can waste limited energy reserves when forced to crawl through equipment and furniture left on the beach overnight. Credits: Jessica Swindall

\section{Always use designated beach walkovers or access} points. Sea turtles use dunes to guide themselves back into the water when they are on land. Dunes block out onshore lights, helping turtles to recognize which direction leads to the ocean. Dunes also help stabilize the beach habitat that sea turtles use for nesting. If you walk over the dunes, you destroy the plants that hold the dunes in place. Without this vegetation, dunes are quickly eroded by wind, which ultimately leads to problems for turtles that become disoriented by lights. Refrain from walking through the dunes when entering and exiting the beach, and never walk above the vegetation line on the beach (Figure 7).

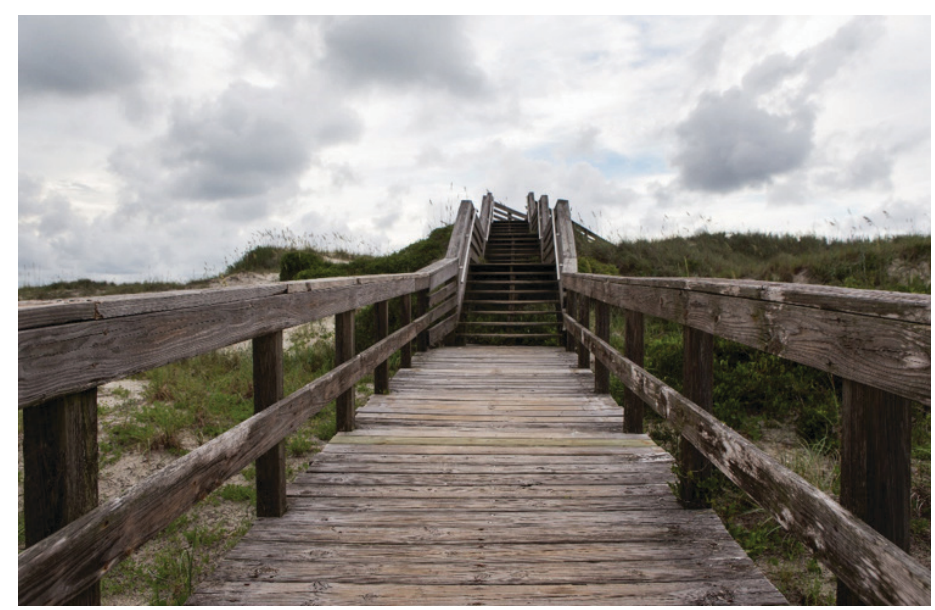

Figure 7. Use designated walkways when crossing over dunes to prevent erosion of these important features.

Credits: Tyler Jones, UF/IFAS
7. Follow best fishing practices for sea turtles. Sea turtles are harmed when they ingest fishing hooks and plastic lures and when they become entangled in fishing lines (Figure 8). Never leave a fishing line unattended, and always properly dispose of fishing lines and old hooks and lures in trash receptacles or recycling containers. If you hook a sea turtle or find one caught on fishing gear, immediately notify the Florida Fish \& Wildlife Conservation Commission (FWC) by calling 1-888-404-FWCC.

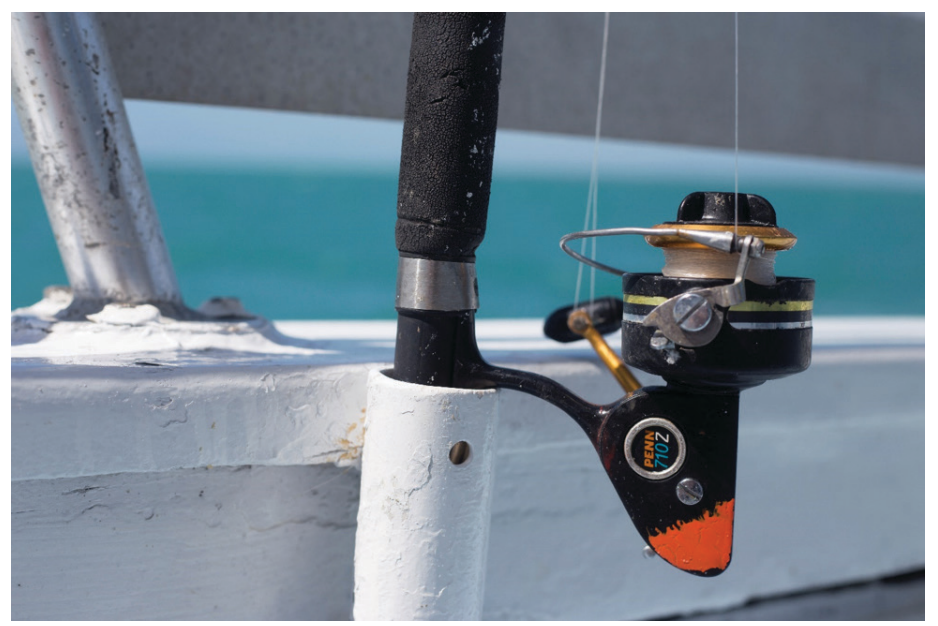

Figure 8. Never leave fishing gear unattended.

Credits: Amy Stuart, UF/IFAS

8. Reduce polluted water run-off. Polluted water run-off can be harmful to sea turtles and their habitats. To minimize the effects of water pollution, never fertilize or irrigate your lawn if rain is forecast within a few hours (Figure 9). Also, consider landscaping with native plants that are adapted to the local growing conditions. These plants are less likely than non-native ornamentals to require extensive fertilization and irrigation.

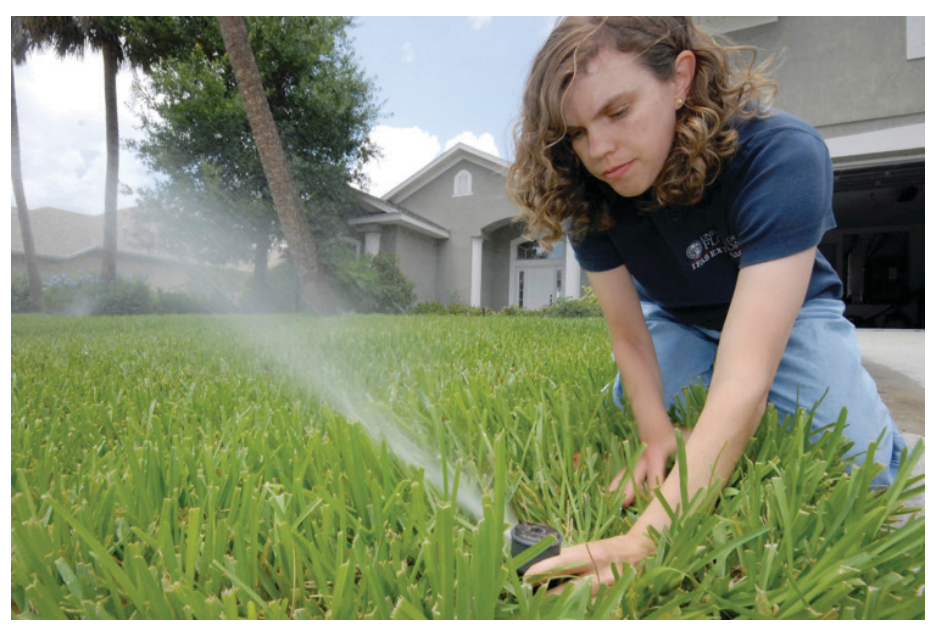

Figure 9. Do not use fertilizer or irrigation prior to heavy rain events to prevent runoff of polluted water.

Credits: UF/IFAS 
9. Do not drive on the beach during nesting or hatching season. The ruts left in the sand after driving vehicles on the beach can entrap hatchlings emerging from their nests (Figure 10). As they crawl to the water, hatchlings can get stuck in vehicle ruts, and then crawl in them for long distances along the beach rather than moving directly to the ocean. This wastes valuable energy that they should spend in the water, swimming to food and safety. Also, driving can destroy vegetation and dunes in the landward part of the beach and disturb shorebirds and their chicks foraging in the wrack line near the water. There is no safe place for people to drive on the beach during turtle nesting season. You can minimize all these dangers to coastal wildlife by avoiding beach driving during the months of May through October.

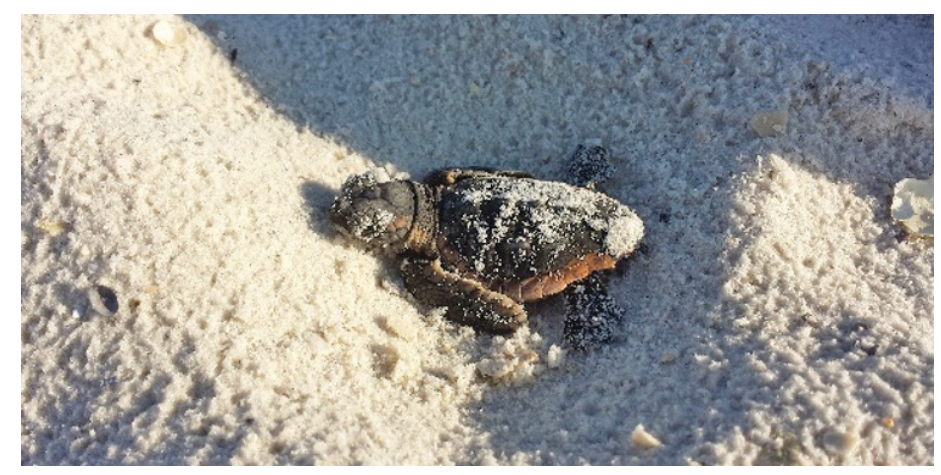

Figure 10. Ruts created by vehicles on the beach can create a hazard for hatching sea turtles trying to move from their nest to the ocean. Credits: Jessica Swindall

10. Observe sea turtles from a safe distance when boating or jet-skiing. When sea turtles are hit by boats or jet skis, they can sustain serious injury or death. When driving a motorized vehicle in the water, drive slowly in areas where sea turtles might be foraging (Figure 11), including shallow waters, reefs, and seagrass beds. Also, never approach a sea turtle with a boat or jet-ski: keep a minimum distance of 50 yards from sea turtles in the water.

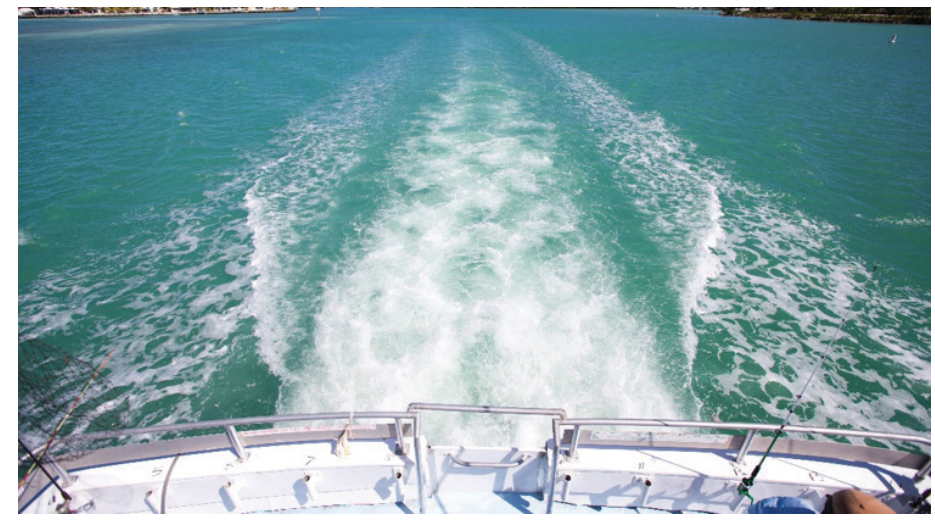

Figure 11. Stay at least 50 yards away from sea turtles when on a motorized boat or jet-ski.

Credits: Amy Stuart, UF/IFAS

\section{Additional Information}

Florida Fish and Wildlife Conservation Commission. 2019a. Species of Sea Turtles Found in Florida. https:// myfwc.com/research/wildlife/sea-turtles/florida/

Florida Fish and Wildlife Conservation Commission. 2019b. Threats to Sea Turtles. https://myfwc.com/research/ wildlife/sea-turtles/threats/

National Oceanic and Atmospheric Administration. 2019. Sea Turtles. https://www.noaa.gov/education/ resource-collections/marine-life-education-resources/ sea-turtles

Swindall, J. E., H. K. Ober, M. M. Lamont, and R. R. Carthy. 2019a. "Informing Sea Turtle Outreach Efforts to Maximize Effectiveness." Wildlife Society Bulletin 43: 436-446

Swindall, J. E., H. K. Ober, M. M. Lamont, and R. R. Carthy. 2019b. Sea Turtle Conservation: Priorities for Environmental Education Efforts. WEC420. Gainesville: University of Florida Institute of Food and Agricultural Sciences. https:// edis.ifas.ufl.edu/uw465

US Fish and Wildlife Service. 2019. General Sea Turtle Information. https://www.fws.gov/northflorida/SeaTurtles/ seaturtle-info.htm 